\title{
ASSOCIATION ANALYSIS OF MAOA AND SLC6A4 GENE VARIATION IN SOUTH EAST EUROPEAN WAR RELATED POSTTRAUMATIC STRESS DISORDER
}

\author{
Nermina Kravicí $^{1,2}$, Emina Šabić Džananović ${ }^{3}$, Mirnesa Muminović Umihanić ${ }^{4}$, \\ Alma Džubur Kulenović ${ }^{3}$, Osman Sinanović ${ }^{2}$, Miro Jakovljević ${ }^{5}$, Dragan Babićc ${ }^{6}$, Abdulah Kučukalić \\ Ferid Agani ${ }^{7}$, Sabina Kučukalić ${ }^{3}$, Alma Bravo Mehmedbašić ${ }^{3}$, Aferdita Goci Uka ${ }^{8}$, \\ Shpend Haxhibeqiri ${ }^{9}$, Valdete Haxhibeqiri ${ }^{8}$, Blerina Hoxha ${ }^{8}$, Branka Aukst Margetić ${ }^{10}$, Nenad Jakšić ${ }^{5}$, \\ Ana Cima Franc ${ }^{5}$, Duško Rudan ${ }^{5}$, Marko Pavlović ${ }^{6}$, Romana Babić ${ }^{6}$, Elma Ferić Bojić ${ }^{11}$, \\ Damir Marjanović ${ }^{11}$, Nada Božina ${ }^{12}$, Christiane Ziegler ${ }^{13}$, Christiane Wolf $^{13}$, Bodo Warrings ${ }^{13}$, \\ Katharina Domschke ${ }^{13}$, Jürgen Deckert ${ }^{13}$ \& Esmina Avdibegović ${ }^{1,2}$ \\ ${ }^{I}$ Department of Psychiatry, University Clinical Centre Tuzla, Tuzla, Bosnia and Herzegovina \\ ${ }^{2}$ School of Medicine, University of Tuzla, Tuzla, Bosnia and Herzegovina \\ ${ }^{3}$ Department of Psychiatry, Clinical Centre University of Sarajevo, Sarajevo, Bosnia and Herzegovina \\ ${ }^{4}$ Community Health Centre Živinice, Živinice, Bosnia and Herzegovina \\ ${ }^{5}$ Department of Psychiatry, University Hospital Centre Zagreb, Zagreb, Croatia \\ ${ }^{6}$ Department of Psychiatry, University Clinical Centre of Mostar, Mostar, Bosnia and Herzegovina \\ ${ }^{7}$ Faculty of Medicine, University Hasan Prishtina, Prishtina, Kosovo \\ ${ }^{8}$ Department of Psychiatry, University Clinical Centre of Kosovo, Prishtina, Kosovo \\ ${ }^{9}$ Institute of Kosovo Forensic Psychiatry, University Clinical Center of Kosovo, Prishtina, Kosovo \\ ${ }^{10}$ Department of Psychiatry, University Hospital Centre Sestre Milosrdnice, Zagreb, Croatia \\ ${ }^{11}$ Department of Genetics and Bioengeneering, International Burch University, Sarajevo, Bosnia and Herzegovina \\ ${ }^{12}$ Department of Laboratory Diagnostics, University Hospital Centre Zagreb, Zagreb, Croatia \\ ${ }^{13}$ Department of Psychiatry, Psychosomatics and Psychotherapy, Centre of Mental Health, \\ University Hospital of Würzburg, Würzburg, Germany
}

received: 6.2.2019;

revised: 15.5.2019;

accepted: 27.5.2019

\section{SUMMARY}

Background: The aim of this study is to investigate the association of gene variations of the monoamine oxidase A (MAOA) and the serotonin transporter solute carrier family 6 member 4 (SLC6A4) gene with posttraumatic stress disorder (PTSD) severity and coping strategies in patients with war related PTSD.

Subjects and methods: The study included 747 individuals who had experienced war trauma in the South Eastern Europe conflicts between 1991 and 1999. Genotyping of the MAOA VNTR and SLC6A4 tandem repeat polymorphism in combination with rs25531 was done in 719 participants: 232 females and 487 males. Among them, 369 have had current or lifetime PTSD and 350 have had no PTSD symptoms. For psychometric approach we used the Clinician Administrated PTSD Scale (CAPS), the Brief Symptom Inventory (BSI), the adapted Hoffman-Lazarus Coping scale and a basic socio-demographic data questionnaire.

Results: There were no significant intergroup (PTSD versus non PTSD) differences in the genotype distribution of MAOA and SLC6A4 gene polymorphisms. The primary finding of our study was that the MAOA short allele (MAOA-S) was nominally significantly associated with the severity of PTSD symptoms in the total subgroup of participants with lifetime PTSD; males for symptoms of hyperarrousal and females with symptoms of re-experience and hyperarousal. In our research the male subsample with current PTSD and MAOA-S genotype had nominally significantly higher scores for some positive coping strategies compared to those carrying the long allele genotype (MAOA-L). There was no significant association between the severity of PTSD symptoms, BSI phenotype, coping scores and the SLC6A4 genotype.

Conclusion: The present results support the notion that MAOA VNTR gene variation modulates development and recovery of posttraumatic stress disorder in a war traumatised population, but did not support a connection between SLC6A4 gene variations and war related PTSD.

Key words: MAOA - SLC6A4 - posttraumatic stress disorder - single nucleotide polymorphisms - neurogenetics

$$
* * * * *
$$

\section{INTRODUCTION}

Wars at the end of the nineties of the $20^{\text {th }}$ century in the region of ex-Yugoslavian countries brought all the cruelty of war vivid again on European ground. These populations were exposed to death, threatened death, actual or threatened serious injury, or actual or threate- ned sexual violence, which fulfil Criterion A - stressor for development of PTSD (DSM-5) (American Psychiatric Association 2013). Up to $35 \%$ of the population exposed to traumatic war experiences developed PTSD symptoms (Priebe et al. 2010, Džubur Kulenović et al. 2016). One of the key questions in trauma related research is why some individuals exposed to a traumatic 
event do develop PTSD and others do not (DiGangi et al. 2013), and what is the influence of genetic predisposition and gene-environment interaction in the etiology of PTSD (Domschke 2012). A twin study estimates the heritability of PTSD within the range from $23 \%$ in male twins (Wolf et al. 2014) to $72 \%$ in female twins (Sartor et al. 2011), and also documented that genetic susceptibilities for PTSD are shared with other mental disorders, particularly major depression (Wolf et al. 2010, Sartor et al. 2011, Sartor et al. 2012). In the last large genome-wide association study (GWAS), the molecular genetics heritability results are consistent with twin studies, and suggest that PTSD heritability among females is higher than among males (Duncan et al. 2017). Genetic studies have identified variations within single genes as potential risk factors for PTSD, and so far more than 25 candidate genes have been investigated (Ryan et al. 2016). Several recent reviews highlight that in the majority of these studies the candidate genes for PTSD were selected based on their known or assumed involvement in the etiology and pathogenesis of PTSD (Domschke 2012, Ryan et al. 2016, Smoller 2016). Geneenvironment-interaction (GxE) studies indicated that environmental exposures such as childhood maltreatment, poverty, and low social support increase the risk of developing PTSD among trauma-exposed individuals (Ryan et al. 2016). Recent studies suggested methylation as an epigenetic mechanism to influence gene regulation and to mediate adaptation to environmental influences and point out their particular relevance for the pathogenesis of PTSD (Ziegler 2017, Domschke 2012).

Earlier studies showed correlations of the genetic variation in the monoamine oxidase A gene (MAOA) with panic disorder (Deckert et al. 1999), depression (Domschke et al. 2008), pathological grief in depression (Kersting et al 2007), and aggressive and antisocial behaviour (Buades-Rotger \& Gallardo-Pujol 2014). The MAOA gene codes the activity of the enzyme monoamine oxidase A which plays a key role in the catabolism of neurotransmitters, including dopamine, norepinephrine and serotonin. Expression of the enzyme correlates with a functional $30 \mathrm{bp}$ variable number tandem repeat (VNTR) polymorphism which is located $1.2 \mathrm{~kb}$ upstream of the MAOA coding sequence. The two most common polymorphisms are the 3- and 4repeat alleles, which are assumed to be associated with decreased and increased transcriptional activity, respectively (Sabol et al. 1998). The functionally more active longer (L) alleles (3a, 4 and 5) were found to be significantly associated with panic disorder in the female subgroups of German and Italian patients (Deckert et al. 1999) which was confirmed in a metaanalytic study conducted by Reif et al. (2012).

Located within the promoter region of the serotonin transporter solute carrier family 6 member 4(SLC6A4) gene, the gene length polymorphism 5-HTTLPR (serotonin-transporter-6 disorders. However, findings have been inconsistent regarding the nature of the relation- ship between the 5-HTTLPR, childhood maltreatment, and anxiety-related traits, with both the short (S) allele andthe long $(\mathrm{L})$ allele having been associated with a risk for developing depression (Caspi et al. 2003, Carli et al. 2011, Kaufman et al. 2004, Laucht et al. 2009), panic disorder (Choe et al. 2013), posttraumatic stress disorder (Grabe et al. 2009, Xie et al. 2009, Xie et al. 2012), social anxiety disorder (Reinelt et al. 2013), and in concern with childhood adversity. Several studies were unable to discern an interactive effect of the 5-HTTLPR and history of abuse on anxiety related phenotypes (Blaya et al. 2010, Cividanes et al. 2014, Zavos et al. 2012), mirroring the failure to identify astrong effect of SLC6A4 gene variations on categorical anxiety phenotypes (Schumacher \& Deckert 2010). The relationship between environmental adversity and individual genetic vulnerability may be further moderated by dynamic processes as a result of positive influences counter acting a GxE risk profile, i.e., elements of successful coping with adversity, thus promoting resilient functioning (Schiele 2016).

Considering the previous findings of the impact of MAOA and SLC6A4 gene variations on panic and depression disorders, the aim of this study was to analyze how the level of posttraumatic stress symptoms, coping strategies and severity of psychological symptoms in a population who survived war trauma is related to the VNTR polymorphisms in MAOA and the SLC6A4 promoter region.

\section{SUBJECTS AND METHODS}

\section{Subjects}

This study is a part of the South Eastern Europe (SEE) - PTSD study about "molecular mechanisms of posttraumatic stress disorder" which was supported by the DAAD (Deutscher Akademischer Austauschdienst). Methods regarding the process of recruitment, study design, diagnostic assessment, inclusion and exclusion criteria and EDTA blood collection of the SEE-PTSD study were described more detailed described by Džubur Kulenović et al. (2016). Participants ( $N=719)$ were recruited in the period from 2013 to 2015 in the five psychiatric centres located in countries whose population had experienced war-related trauma between 1991 and 1999: Zagreb in Croatia (1991-1992), Sarajevo, Tuzla and Mostar in Bosnia and Herzegovina (19921995), and Prishtina in Kosovo (1999-1999). The inclusion criteria were that participants were at least 16 years of age at the time of traumatization and not older than 65 years of age at time of recruitment. Exclusion criteria were: intellectual disability $(\mathrm{MMSE}<25)$, organic and brain trauma related disorders, epilepsy, psychotic disorders, addiction disorders except smoking, oncological illnesses, medication known to affect methylation status, e.g, valproic acid, $1^{\text {st }}$ and $2^{\text {nd }}$ degree relation to an already recruited person. Interviews were performed by medical personnel (psychiatrists, psychologists or psychiatric residents) after training of the principal investigators. 
After recruitment altogether 719 participants (mean age $49.4 \pm 7.9 ; 487$ males) were divided into three experimental groups. The first group consisted of 218 patients (mean age 50.1 \pm 6.7 ; 157 males) with current PTSD, the second comprised 151 participants with lifetime PTSD (mean age 49.5 \pm 8.2 ; 98 males) and finally the last group included 350 healthy volunteers with no diagnosable PTSD (mean age $48.8 \pm 8.5 ; 232$ males).

\section{Ethical Votes}

Ethical votes at the participating clinical centers were obtained between 2011 and 2013 on the basis of local translations of an information and consent form designed by the Würzburg center. All participants thus were informed and gave written informed consent according to the principles of the declaration of Helsinki (WMA 2013).

\section{Psychometric Instruments}

Participants' presence or absence symptoms of PTSD in screening stage were assessed using the Structured Clinical Interview M.I.N.I. (Mini International Neuropsychiatric Interview). The Clinician Administrated PTSD Scale (CAPS) (Blake et al. 1995) was used to make a categorical PTSD diagnosis and to assess the severity of symptom of PTSD. For the assessment of psychological symptoms we used the Brief Symptom Inventory (BSI) (Derogatis \& Melisaratos 1983). The BSI is a self-report symptom scale composed of nine primary symptom dimensions and includes three global indices of distress (Global Severity Index, Positive Symptom Distress Index, and Positive Symptom Total), which measure the overall psychological distress level, the intensity of symptoms, and the number of selfreported symptoms. The reliability of the BSI for the present sample was high (Cronbach $\alpha=0.987$ ). For the assessment of ways of coping the adopted HoffmanLazarus Coping Scale (Arcel \& Ljubotina 1995) with eight subscales was used. The subscales are: social support, confrontation, distancing, self control, positive reappraisal, planned problem solving, escape-avoidance, accepting responsibility. The reliability of the Coping scale for the present sample was high (Cronbach $\alpha=0.835$ ). Also, socio-demographic data were collected.

\section{Molecular analyses}

Molecular analyses were performed in the Laboratory of Functional Genomics at the Department of Psychiatry Psychosomatics and Psychotherapy, Würzburg. Prior genotyping, genomic DNA was isolated from frozen venous EDTA-blood using the FlexiGene DNA Kit (Qiagen, Hilden, Germany) according to manufacturer's instructions and stored until use at $-80^{\circ} \mathrm{C}$.

The best-described common genetic variation of the MAOA gene is a $30 \mathrm{bp}$ variable number of tandem repeat
(VNTR) polymorphism in the promoter region termed MAOA-uVNTR. Within this study MAOA-uVNTR genotypes (2,3,3.5,4, and 5), which represent the amount of repeats in the distinct samples were determined according to previously published protocols (Reif et al. 2013). Because of its $X$ chromosomal location (Xp11.4-p11.3), males have only one allele, while females have two alleles. According to their influence on MAOA enzyme activity (Reif 2014) all 'short' S alleles ( 2 and 3 repeats) were grouped to the ,MAOA$\mathrm{S}$ " group (females with two $\mathrm{S}$ alleles and males with one $\mathrm{S}$ allele) and in statistical analysis compared to the 'long' L (3.5, 4 and 5 repeats) alleles labelled as "MAOA-L" group (considered females with two L alleles, females with one $\mathrm{S}$ and one $\mathrm{L}$ allele, and males with one $\mathrm{L}$ allele) according to a dominant model. Because of the evidence that "high active" long alleles confer risk to develop panic disorder in females (Reif, 2014), we perfomed also sex-specific analysis, for males and females, respectively.

Genes engaged in the serotonergic pathways are regarded as candidate genes due to the documented role of serotonin in the etiopathogenesis of mood disorders. One of the most often investigated genes of this group is the SLC6A4, located on the human chromosome 17q11.2. 17q12. Within this study we examined the most extensively investigated serotonin transporter gene linked polymorphic region 5-HTTLPR, which is characterized by an insertion or deletion of a $44 \mathrm{bp}$ sequence in combination with rs25531. The short allele (S) with the $44 \mathrm{bp}$ deletion was found to have a three times lower transcriptional activity than the long allele (L) including a 44-bp insertion (Grochans 2015, Schiele 2016, Lesch 1996). Genotyping of the 5-HTTLPR was done following previously published protocols (Schiele 2016).

MAOA genotyping was successfully done in 704 participants, and SLC6A4 genotyping was successfully done in 678 participants, reaching a genotyping call rate of at least $94 \%$. All polymorphisms did not deviate from Hardy-Weinberg equilibrium $(\mathrm{p}>0.3)$. The MAOA and SLC6A4 allele and genotype distributions in PTSD groups and control sample are given in Table 1.

\section{Statistical analyses}

Statistics were performed using R v. 3.3.1 (R Foundation for Statistical Computing, Vienna, Austria) and SPSS Statistics, version 22. The $\chi^{2}$ test was used for case-control analyses and the Mann-Whitney U test was carried out for CAPS and BSI analyses, and coping strategies. A significance level was Bonferroni adjusted for 23 variants that were analyzed in total in the entire project ( $\alpha=0.002$ ) (Džubur Kulenović et al. 2016). Within the two groups of patients, i.e. individuals with lifetime or current PTSD, linear regression was carried out individually for analyses on the dimensional CAPS and BSI scores. For MAOA, carriers of no other than the $\mathrm{S}$ allele (homozygous females, hemizygous males) were tested 
Table 1. Genotype distribution of the MAOA and SLC6A4 gene in the sample of war traumatized individuals (N=704)

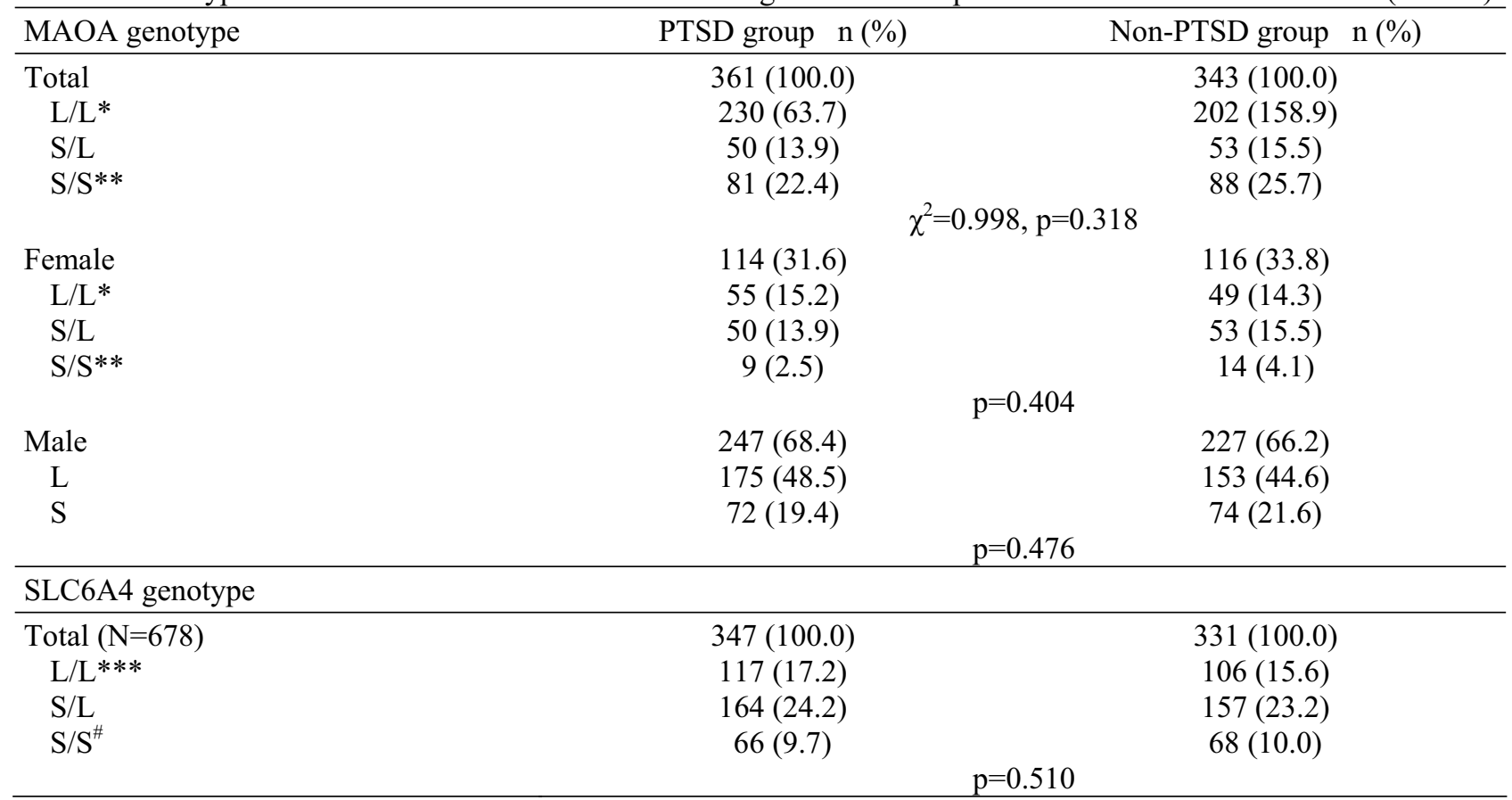

MAOA: monoamino oxidase A; VNTR - variable number of tandem repeat; SLC6A4 - serotonin transporter gene;

${ }^{*} \mathrm{~L}$ - long group belong all alleles with 3.5, 4, or 5 repeats of the VNTR; **S - short group belong all alleles with 2 and 3 repeats of the VNTR; *** L - high-expressing long allele; ${ }^{\#} \mathrm{~S}$ - low-expressing short allele; PTSD - posttraumatic stress disorder

against individuals carrying any other genotype combination (i.e. carriers of at least one $\mathrm{L}$ allele). Males and females were analyzed separately. Concerning SLCA4, homozygous individuals with the long-rs25531 (A) allelic combination (LALA) were tested against individuals with any other 5-HTTLPR genotype.

\section{RESULTS}

\section{Monoamine Oxidase A (MAOA)}

There were no significant differences between the PTSD and non-PTSD group in genotype distributions of the MAOA $\left(\chi^{2}=0.998, p=0.318\right)$ (Table 1). According to the severity of PTSD symptoms (CAPS) we found that in the lifetime PTSD group individuals of the MAOA-S group compared to those of the MAOA-L group showed nominally significant higher score of the CAPS total and symptoms of hyperarousal (Table 2). Also, females with lifetime PTSD and MAOA-S genotype had nominal significantly higher CAPS total scores, symptoms of reexperience and hyperarousal than females carrying the MAOA-L genotype (Figure 1, Table 2). Finally, also males with the MAOA-S genotype (short allele carriers) and lifetime PTSD had significantly higher score of CAPS total and symptoms of hyperarousal than males with MAOA-L genotype (long allele carriers) (Figure 2, Table 2) at a nominal level. There were no significant difference in severity of PTSD symptoms between MAOA-S and MAOA-L group in the subgroup of participants with current PTSD for the total sample, neither between males or females $\left(\mathrm{p}_{\mathrm{all}}>0.05\right)$.

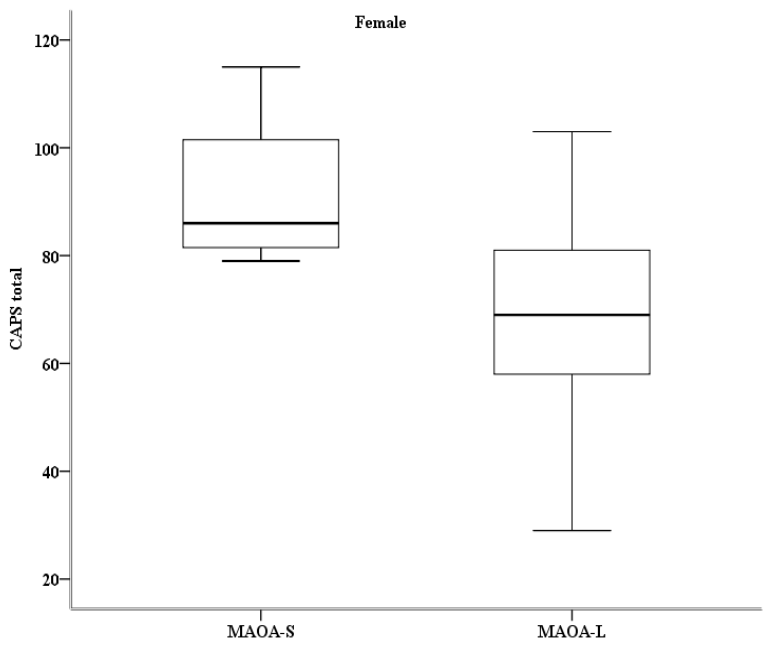

MAOA-S:females with short allele homozygous;

MAOA-L: females long allele homozygous and heterozygous

Figure 1. The distribution of CAPS values according to MAOA VNTR lengths in female lifetime PTSD subgroup $(\mathrm{N}=53 ; \mathrm{p}=0.018)$

There were no differences in BSI scores between the MAOA genotype groups in either males or females with lifetime PTSD or current PTSD ( $\left.\mathrm{p}_{\text {all }}>0.05\right)$. Regarding the severity of the psychological symptoms there were some differences in the total subsample of current PTSD patients where the MAOA-S group had slightly higher but not nominally significant BSI total scores than the MAOA-L group $(Z=-1.929, p=0.054)$, especially for symptom obsessive-compulsive $(Z=-2.612$, $\mathrm{p}=0.009$ ). 
Table 2. Differences in severity of PTSD symptoms between the MAOA genotype groups

\begin{tabular}{|c|c|c|c|c|}
\hline \multirow[b]{2}{*}{ Sample } & \multicolumn{4}{|c|}{ MAOA genotype groups } \\
\hline & PTSD symptoms & $\begin{array}{c}\mathrm{S} \\
\mathrm{M} \pm \mathrm{SD} \text { (Median) }\end{array}$ & $\begin{array}{c}\mathrm{L} \\
\mathrm{M} \pm \mathrm{SD} \text { (Median) }\end{array}$ & Mann-Witney U test \\
\hline Lifetime PTSD & bgroup & & & \\
\hline $\begin{array}{l}\text { Male; } n(\%) \\
\quad(\mathrm{N}=92)\end{array}$ & $\begin{array}{l}\text { CAPS total } \\
\text { Re-experience } \\
\text { Avoidance } \\
\text { Hyperarousal }\end{array}$ & $\begin{array}{c}26(28.3) \\
70.5 \pm 16.79(74.5) \\
21.73 \pm 5.52(22.0) \\
26.19 \pm 7.94(26.0) \\
22.58 \pm 5.53(23.5)\end{array}$ & $\begin{array}{c}66(71.7) \\
63.59 \pm 17.42(65.0) \\
20.13 \pm 5.81(20.0) \\
23.87 \pm 7.64(25.0) \\
19.59 \pm 6.56(19.5)\end{array}$ & $\begin{array}{l}Z=-1.99, p=0.046 \\
Z=-1.56, p=0.118 \\
Z=-1.36, p=0.174 \\
Z=-2.09, p=0.037\end{array}$ \\
\hline $\begin{array}{l}\text { Female; } \mathrm{n}(\%) \\
\qquad(\mathrm{N}=53)\end{array}$ & $\begin{array}{l}\text { CAPS total } \\
\text { Re-experience } \\
\text { Avoidance } \\
\text { Hyperarousal }\end{array}$ & $\begin{array}{c}4(7.5) \\
91.50 \pm 16.09(86.0) \\
29.25 \pm 2.75(29.5) \\
33.50 \pm 9.68(29.0) \\
28.75 \pm 5.12(27.5)\end{array}$ & $\begin{array}{c}49(92.5) \\
67.98 \pm 17.27(69.0) \\
22.73 \pm 6.39(22.0) \\
25.82 \pm 8.02(26.0) \\
19.43 \pm 6.31(20.0)\end{array}$ & $\begin{array}{l}Z=-2.37, p=0.018 \\
Z=-2.14, p=0.032 \\
Z=-1.53, p=0.125 \\
Z=-2.58, p=0.010\end{array}$ \\
\hline
\end{tabular}

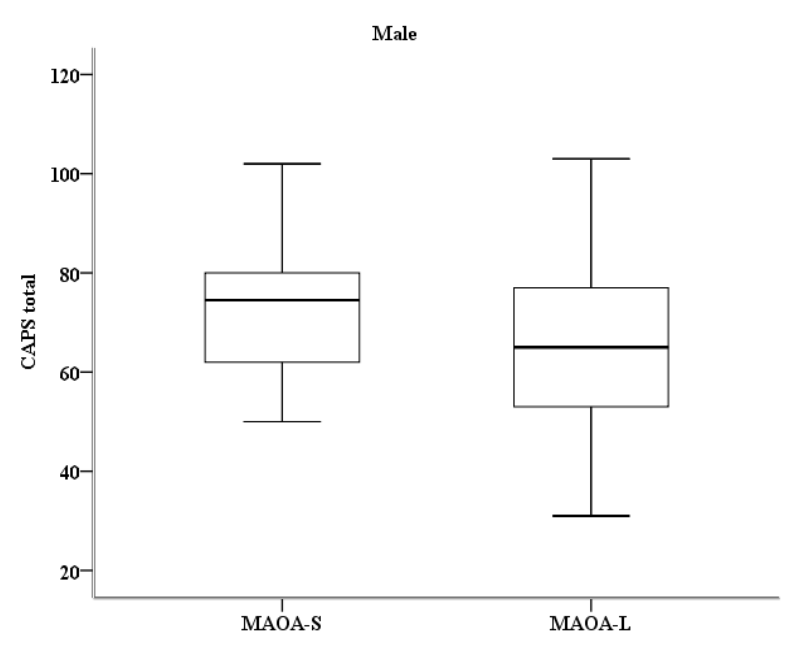

MAOA-S:males with short allele; MAOA-L: males with long allele

Figure 2. The distribution of CAPS values according to MAOA VNTR lengths in male lifetime PTSD subgroup $(\mathrm{N}=92 ; \mathrm{p}=0.046)$

Total score of positive strategies did not differ significantly between MAOA-S and MAOA-L group in females with PTSD, as well as with lifetime PTSD and current PTSD subgroups $\left(\mathrm{p}_{\mathrm{all}}>0.05\right)$. Also, there were no significant differences between MAOA genotype groups in total score of negative strategies neither in females with PTSD, nor in those suffering from lifetime PTSD and current PTSD ( $\left.\mathrm{p}_{\mathrm{all}}>0.05\right)$. However, in females with current PTSD we found that MAOA-L group showed significantly lower scores in escape avoidance strategies $(Z=-2.441, p=0.015)$ compared with MAOA-S group at a nominal level. The total score of positive coping strategies did not differ significantly for males with PTSD, as well as in the lifetime PTSD subgroup $\left(\mathrm{p}_{\mathrm{all}}>0.05\right)$. Also, there was no significant difference between MAOA genotype groups in total score of negative coping strategies in males with PTSD, lifetime PTSD and current PTSD ( $\left.\mathrm{p}_{\mathrm{all}}>0.05\right)$. In male subsample with current PTSD we found though, that carrier of the short allele (MAOA-S group) had a nominal significantly higher average score of positive distancing $(Z=-2.611, \mathrm{p}=0.009)$, accepting responsibility $(Z=-2.401, p=0.016)$ and total score of positive coping strategies $(Z=-2.142, p=0.032)$ compared to those with long allele (MAOA-L group).

\section{Solute carrier family 6 member 4 (SLC6A4)}

There were neither significant differences between the PTSD and non-PTSD group in genotype distributions of the SLC6A4 gene $\left(\chi^{2}=0.348, p=0.840\right)$ (Table $1)$, nor any difference in CAPS, BSI and positive or negative coping scores between SLC6A4 genotype groups in the PTSD group, in the current PTSD subgroup and in the lifetime PTSD subgroup ( $\left.\mathrm{p}_{\text {all }}>0.05\right)$.

\section{DISCUSSION}

The primary finding of our study was that the MAOA short allele was nominally significantly associated with the severity of PTSD symptoms in the total subgroup of participants with lifetime PTSD, as well as in females and males when analyzed individually within this patient subgroup. Subgroup MAOA-S males with lifetime PTSD showed a nominally significant higher association for symptoms of hyperarousal, and subgroup MAOA-S female with lifetime PTSD was nominally significantly higher associated with symptoms of reexperience and hyperarousal. Our results are in accordance with previous researches that short MAOA VNTR alleles (MAOA-S) are associated with impulsive aggressive behaviour (Reif et al. 2014). Increased aggression might not be a baseline trait in short allele carriers, but rather may occur in response to provocation (McDermot et al. 2009), underscoring the role of threatening stimuli in emotional processing. 
In our research the male subsample with current PTSD and short allele genotype (MAOA-S group) had a nominally significantly higher score of positive distancing, accepting responsibility and total score of positive coping strategies compared to those carrying the long allele genotype (MAOA-L group). That finding may correspond with previous research where MAOA-S genotypes significantly influenced the regulation of automatic approach-avoidance reactions (Ernst et al. 2013).

Long alleles of the MAOA VNTR promoter polymorphism are associated with panic disorder and correspond to an increased enzyme activity. Carriers of the risk allele had significantly worse outcomes of cognitive behavioural treatment (CBT) as measured by the Hamilton Anxiety scale (Reif et al. 2014). In women with current PTSD our findings showed that high MAOA activity is a risk factor of avoidance at the genetic or epigenetic level.

Previous research emphasised MAOA hypermethylation as a risk factor for the development of current PTSD in males (Ziegler et al. 2017) while reversibility of hypomethylation is a potential epigenetic correlate for psychotherapy success of panic disorder in females (Ziegler et al. 2016). Our findings are consistent with the hypothesis derived from methylation studies considering low MAOA activity as a risk factor for genetic predisposition to PTSD in males.

There are a number of studies showing that short repeats (MAOA-S) are associated with impulsive-aggressive behaviour in males (Kim-Cohen et al. 2006, Reif et al. 2007); in contrast, long alleles are associated with panic disorder in females (Deckert et al. 1999, Maron et al. 2005, Samochowiec et al. 2004). This phenomenon has been dubbed the 'warrior vs worrier-gene' dichotomy (Gibbons 2004) as different alleles of MAOA apparently are associated with aggression (low-activity, males) as well as anxiety (high-activity, females). Attempts to understand the neural mechanisms linking altered gene expression to neural systems are manifold and demonstrated MAOA to mediate environmental effects and a heightened sensitivity to aversive experiences in short allele carriers (McDermott et al. 2009).

A complex, but hypothetical model provides a framework of how genetic variation of MAOA might predispose to dysfunctional 'flight' behaviour - that is, panic attacks and PTSD symptoms of hyperarousal - by modulating serotonin and norepinephrine levels in neural networks. Carriers of the low-expressing compared to the high-expressing genetic variant (MAOA) showed increasing regulatory activity in the right dorsolateral prefrontal cortex (DLPFC) during incompatible conditions (approach negative, avoid positive) (Ernst et al. 2013). MAOA genotypes have been investigated with regard to personality traits, where carriers of the lowexpressing genetic variant (MAOA) repeatedly, but not always (Haberstick et al. 2005), showed enhanced trait impulsivity (Huang et al. 2004) and even aggressive, criminal behaviour (Nilsson et al. 2006). On the other hand, female carriers of high-expressing alleles are more prone to develop panic disorder (Reif et al. 2012).
In our research we did not get a significant correlation of SLC6A4 variants and war related PTSD. We identified some nominal significance regarding the correlation of SLC6A4 and symptoms of psychoticism and slightly trending but not significant results concerning hostility. 5HTTLPR/rs25531 carriers of the more active LALA genotype consistently scored highest on all considered measures of anxiety if they had a history of childhood adversity, but only when general self-efficacy was low (Schiele et al. 2015). The 'differential susceptibility hypothesis' (Belsky \& Pluess 2009, Belsky et al. 2009) proposing the term "plasticity genes" rather than "risk genes", implicates that a given genotype does not convey vulnerability for anxiety per se, but is subject to both positive and negative environmental influences. Genes seem to drive differential sensitivity to environmental conditions as a whole, and depending on the nature of these environmental influences, their contribution can be beneficial or harmful and manifest on a phenotypic level.

\section{CONCLUSIONS}

Limitations of this study are the relatively small sample size and a low statistical power. After Bonferroni correction for multiple tests none of the nominally significant MAOA results remained significant and thus are to be considered exploratory and hypothesis generating. Further studies ought to be conducted to test MAOA polymorphisms for associations with more refined personality traits conferring vulnerability to anxiety, impulsivity and aggression as well as psychological strengths and capacity for recovery in accordance with different environmental factors, rather than with categorical psychiatric diagnosis.

\section{Acknowledgements:}

We thank all the participants and their families without whose idealistic and enthusiastic support the study would not have been possible. We also would like to thank at Sarajevo: the Association of Women Victims of War and Bakira Hasecic, the Association of Physically Handicapped, Zilko Buljugija, Zoran Budimlija, MD, PhD, Jasminka Krehic, MD, PhD, Elvira Sabanovic, RSN and Subhija Gusic; in Kosovo: Feride Rushiti, MD, Selvije Izeti, MSc, Vjosa Devaja, MD, Melita Kallaba, MD from Kosova Rehabilitation Center for Trauma Survivors- KRCT; Emirjeta Kumnova, Veprore Shehu from Medica Kosova; Zahrije Podrimqaku Subashi from the Association of Political Prisoners, Kadire Tahiraj from the Center for Promotion of Women's Rights; Arbërore Ulaj, MD, Teuta Haxhiu, MD and Drita Gashi, MD, for their assistance in recruiting and interviewing participants; at Zagreb: Mirica Mavracic, Zoran Bradas, Zrinka Mirkovic and Maja Mezak Herceg for technical assistance in drawing blood and extracting DNA; at Tuzla: the staff of the Department of Transfusion of University Clinical Center of Tuzla, and the staff of the Department of Psychiatry, in particular Emina Hujdur, Medin Omerašević and Avdo Šakušić, MD for technical support and Maja Brkić and Sandra Zornić for their assistance in data collection; at Würzburg: Carola Gagel for technical assistance with extracting DNA. Thanks are highly deserved by and gratefully extended to Peter Riederer as spiritus rector who brought the consortium together. The study was funded by the DAAD program Stability Pact for South Eastern Europe and supported by the DFG-funded RTG 1253 (speaker Pauli) as well as the DFG-funded CRC-TRR58 (projects C02 Domschke, Deckert, and Z02 Deckert, Domschke). 


\section{Conflict of interest: None to declare.}

\section{Contribution of individual authors:}

Each author has actively participated in the international research project (see Acknowledgments) and, therefore, has substantially contributed to the development and publication of this manuscript.

\section{References}

1. American Psychiatric Association: Diagnostic and statistical manual of mental disorders. 5th Edition. American Psychiatric Association, Washington, DC, 2013

2. Arcel LT \& Ljubotina D: Assesment of psycho-social status and treatment of refugee women and their families. In: Arcel LT, Folnegović-Smalc V, Tocilj-Simunković G, Kozarić-Kovačić D \& Ljubotina D (eds). Psychosocial help to war victims: women refugees and their families, 114-117. Zagreb: Nakladništvo Lumin, 1995

3. Blake DD, Weathers FW, Nagy LM, Kaloupek DG, Gusman FD, Charney DS \& Keane TM: The development of a clinician-administered PTSD scale. J Trauma Stress 1995; 8:75-90

4. Blaya C, Salum GA, Moorjani P, Seganfredo AC, Heldt E, Leistner-Segal S, Smoller JW \& Manfro GG: Panic disorder and serotonergic genes (SLC6A4, HTRIA and HTR2A): association and interaction with childhood trauma and parenting. Neurosci Lett 2010; 485:11-15. doi:10.1016/j.neulet.2010.08.042

5. Belsky $J \&$ Pluess M: Beyond diathesis stress: differential susceptibility to environmental influences. Psychol Bull 2009; 135:885-908. doi:10.1037/a0017376

6. Belsky J, Jonassaint C, Pluess M, Stanton M, Brummett B \& Williams R: Vulnerability genes or plasticity genes? Mol Psychiatry 2009; 14:746-754. doi:10.1038/mp.2009.44

7. Buades-Rotger $M \&$ Gallardo-Pujol D: The role of the monoamine oxidase A gene in moderating the response to adversity and associated antisocial behavior: a review. Psychol Res Behav Manag 2014; 7:185-200

8. Carli V, Mandelli L, Zaninotto L, Roy A, Recchia L, Stoppia $L$ et al.: A protective genetic variant for adverse environments? The role of childhood traumas and serotonin transporter gene on resilience and depressive severityin a high-risk population. Eur Psychiatry 2011; 26:471-478. doi:10.1016/j.eurpsy.2011.04.008

9. Caspi A, Sugden K, Moffitt TE, Taylor A, Craig IW, Harrington $H$ et al.: Influence of life stress on depression: moderation by apolymorphism in the 5-HTT gene. Science 2003; 301:386-389

10. Choe AY, Kim B, Lee KS, Lee JE, Lee JY, Choi TK \& Lee SH: Serotonergic genes (5-HTT and HTR1A) and separation lifeevents: gene-by-environment interaction for panic disorder. Neuropsychobiology 2013; 67:192-200. doi:10.1159/000347084

11. Cividanes GC, Mello AF, Sallum JM, Fossaluza V, Medeiros M, Maciel MR et al.: Lack of association between the 5-HTTLPR and positive screening for mental disorders among children exposed to urban violence and maltreatment. Rev Bras Psiquiatr 2014; 36:277-284. doi:10.1590/1516-4446-2013-1150

12. Deckert J, Catalano M, Syagailo YV, Bosi M, Okladnova $O$, Di Bella D et al.: Excess of high activity monoamine oxidase A gene promoter alleles in female patients with panic disorder. Hum Mol Genet 1999; 8:621-624
13. Derogatis L \& Melisaratos N: The Brief Symptom Inventory: A introductory report. Psychol Med 1983; 13:595-605

14. DiGangi J, Guffantiz G, McLaughlina KA \& Koenen C: Considering trauma exposure in the context of genetics studies of posttraumatic stress disorder: a systematic review. Biol Mood Anxiety Disord 2013; 3:2. http://doi.org/10.1186/2045-5380-3-2

15. Domschke K, Hohoff C, Mortensen LS, Roehrs T, Deckert $J$, Arolt V \& Baune BT: Monoamine oxidase A variant influences antidepressant treatment response in female patients with major depression. Prog Neuropsychopharmacol Biol Psychiatry 2008; 32:224-228

16. Domschke K: Patho-genetics of posttraumatic stress disorder. Psychiatr Danub 2012; 24:267-273

17. Duncan LE, Ratanatharathorn A, Aiello AE, Almli LM et al.: Largest GWAS of PTSD (N=20070) yields genetic overlap with schizophrenia and sex differences in heritability. Mol Psychiatry 2017; 00:1-8. doi:10.1038/mp.2017.77

18. Džubur Kulenović A, Agani F, Avdibegović E, Jakovljević M, Babić D, Kučukalić A et al.: Molecular Mechanisms of Posttraumatic Stress Disorder (PTSD) as a Basis for Individualized and Personalized Therapy: Rationale, Design and Methods of the South Eastern Europe (SEE)PTSD study. Psychiatr Danub 2016; 28:154-163

19. Ernst L, Lutz E, Ehlis AC, Fallgatter A, Reif A \& Plichta M: Genetic Variation in MAOA Modulates Prefrontal Cortical Regulation of Approach-Avoidance Reactions. Neuropsychobiology 2013; 67:168-180

20. Gibbons A: American Association of Physical Anthropologists meeting. Tracking the evolutionary history of a "warrior" gene. Science 2004; 304:818

21. Grabe HJ, Spitzer C, Schwahn C, Marcinek A, Frahnow A, Barnow $S$ et al.: Serotonin transporter gene (SLC6A4) promoter polymorphisms and the susceptibility to posttraumatic stress disorder in the general population. Am J Psychiatry 2009; 166:926-933. doi:10.1176/appi.ajp.2009.08101542

22. Grochans E, Jurczak A, Szkup M, Samochowiec A, Wloszczak-Szubzda A, Karakiewicz B et al: Evaluation of the Relationship between 5-HTT and MAO Gene Polymorphisms, Mood and Level of Anxiety among Postmenopausal Women. Int J Environ Res Public Health 2015; 12:268-281. doi:10.3390/ijerph120100268

23. Haberstick BC, Lessem JM, Hopfer CJ, Smolen A, Ehringer MA, Timberlake D \& Hewitt JK: Monoamine oxidase A (MAOA) and antisocial behaviours in the presence of childhood and adolescent maltreatment. Am J Med Genet B Neuropsychiatr Genet 2005; 135B:59-64

24. Huang YY, Cate SP, Battistuzzi C, Oquendo MA, Brent D \& Mann JJ: An association between a functional polymorphism in the monoamine oxidase A gene promoter, impulsive traits and early abuse experiences. Neuropsychopharmacology 2004; 29:1498-1505

25. Kaufman J, Yang BZ, Douglas-Palumberi H, Houshyar S, Lipschitz D, Krystal JH \& Gelernter J: Social supports and serotonin transporter gene moderate depression in maltreated children. Proc Natl Acad Sci USA 2004; 101:17316-17321

26. Kersting A, Kroker K, Horstmann J, Baune BT, Hohoff C, Mortensen LS et al.: Association of MAO-A with variant with complicated grief in major depresion. Neuropsyhobiology 2007; 56:191-196. doi: 10.1159/000120624

27. Kim-Cohen J, Caspi A, Taylor A, Williams B, Newcombe R, Craig IW et al.: MAOA, maltreatment, and gene-environment interaction predicting children's mental health: new evidence and a meta-analysis. Mol Psychiatry 2006; 11:903-913 
28. Laucht M, Treutlein J, Blomeyer D, Buchmann AF, Schmid B, Becker $K$ et al.: Interaction between the 5HTTLPR serotonin transporter polymorphism and environmental adversity for mood and anxiety psychopathology: evidence from a highrisk community sample of young adults. Int $J$ Neuropsychopharmacol 2009; 12:737-747. doi:10.1017/S1461145708009875

29. Lesch KP, Bengel D, Heils A, Sabol SZ, Greenberg BD, Petri $S$ et al.: Association of anxiety-related traits with a polymorphism in the serotonin transporter gene regulatory region. Science 1996; 274:1527-1531

30. Maron E, Lang A, Tasa G, Liivlaid L, Toru I, Must A et al.: Associations between serotonin-related gene polymorphisms and panic disorder. Int $J$ Neuropsychopharmacology 2005; 8:261-266

31. McDermott R, Tingley D, Cowden J, Frazzetto $G$ \& Johnson DD: Monoamine oxidase A gene (MAOA) predicts behavioral aggression following provocation. Proc Natl Acad Sci USA 2009; 106:2118-2123

32. Nilsson $K W$, Sjoberg RL, Damberg M, Leppert J, Ohrvik J, Alm PO, Lindstrom L \& Oreland L: Role of monoamine oxidase A genotype and psychosocial factors in male adolescent criminal activity. Biol Psychiatry 2006; 59:121-127

33. Priebe $S$, Bogic M, Ajdukovic D, Franciskovic T, Galeazzi GM, Kucukalic A et al.: Mental disorders following war in the Balkans: a study in 5 countries. Arch Gen Psychiatry 2010; 67:518-528

34. Reif A, Rosler M, Freitag CM, Schneider M, Eujen A, Kissling $C$ et al.: Nature and nurture predispose to violent behavior: serotonergic genes and adverse childhood environment. Neuropsychopharmacology 2007; 32:2375-2383

35. Reif A, Weber H, Domschke K, Klauke B, Baumann C, Jacob $C P$ et al.: Meta-analysis argues for a female specific role of MAOA-uVNTR in panic disorder in four European populations. Am J Med Genet B Neuropsychiatr Genet 2012; 159B:786-793

36. Reif A, Richter J, Straube J, Höfler M, Lueken U, Gloster AT et al.: MAOA and mechanisms of panic disorder revisited: from bench to molecular psychotherapy. Mol Psychiatry 2014; 19:122-128

37. Reinelt E, Aldinger M, Stopsack M, Schwahn C, John U, Baumeister SE et al.: High social support buffers the effects of 5-HTTLPR genotypes within social anxiety disorder. Eur Arch Psychiatry Clin Neurosci 2014; 264:433-439

38. Ryan J, Chaudieu I, Ancelin ML \&Saffery R: Biological underpinnings of trauma and post-traumatic stress disorder: focusing on genetics and epigenetics. Epigenomics 2016; 8:1553-1569

39. Sabol SZ, Hu S \& Hamer D: A functional polymorphism in the monoamine oxidase A gene promoter. Hum Genet 1998; 103:273-279

40. Samochowiec J, Hajduk A, Samochowiec A, Horodnicki J, Stepien G, Grzywacz A et al.: Association studies of MAO$A$, COMT, and 5-HTT genes polymorphisms in patients with anxiety disorders of the phobic spectrum. Psychiatry Res 2004; 128:21-26
41. Sartor CE, McCutcheon VV, Pommer NE, Nelson EC, Grant JD, Duncan AE et al.: Common genetic and environmental contributions to post-traumatic stress disorder and alcohol dependence in young women. Psychol Med 2011; 41:1497-1505

42. Sartor CE, Grant JD, Lynskey MT, McCutcheon VV, Waldron M, Statham DJ et al.: Common heritable contributions to low-risk trauma, high-risk trauma, posttraumatic stress disorder, and major depression. Arch Gen Psychiatry 2012; 69:293-299

43. Schiele M, Ziegler C, Holitschke K, Schartner C, Schmidt $B$, Weber $H$ et al.: Influence of 5-HTT variation, childhood trauma and self-efficacy on anxiety traits: a geneenvironment-coping interaction study. J Neural Transm 2016; 123:895-904

44. Schumacher J \& Deckert J: Serotonin transporter polymorphisms and panic disorder. Genome Med 2010; 2:40. doi:10.1186/gm161

45. Smoller JW: The genetics of stress-related disorders: PTSD, depression, and anxiety disorders. Neuropsychopharmacology 2016; 41:297-319

46. Wolf EJ, Mitchell KS, Koenen KC \& Miller MW: Combat exposure severity as a moderator of genetic and environmental liability to post-traumatic stress disorder. Psychol Med 2014; 44:1499-1509

47. Wolf E, Miller M, Krueger R, Lyons M, Tsuang $M$ \& Koenen K: Posttraumatic Stress Disorder and the Genetic Structure of Comorbidity. J Abnorm Psychol 2010; 119:320-330

48. Xie P, Kranzler HR, Poling J, Stein MB, Anton RF, Brady $K$ et al.: Interactive effect of stressful life events and the serotonin transporter 5-HTTLPR genotype on posttraumatic stress disorder diagnosis in 2 independent populations. Arch Gen Psychiatry 2009; 66:1201-1209. doi:10.1001/archgenpsychiatry.2009.153

49. Xie P, Kranzler HR, Farrer L \& Gelernter J: Serotonin transporter 5-HTTLPR genotype moderates the effects of childhood adversity on posttraumatic stress disorder risk: a replication study. Am J Med Genet B Neuropsychiatr Genet 2012; 159B:644-652. doi:10.1002/ajmg.b.32068

50. Zavos HM, Wong CC, Barclay NL, Keers R, Mill J, Rijsdijk FV et al.: Anxiety sensitivity in adolescence and young adulthood: the role of stressful life events, 5HTTLPR and their interaction. Depress Anxiety 2012; 29:400-408

51. Ziegler C, Richter J, Mahr M, Gajewska A, Schiele MA, Gehrmann A et al.: MAOA gene hypomethylation in panic disorder - reversibility of an epigenetic risk pattern by psychotherapy. Transl Psychiatry 2016; 6:e773. doi:10.1038/tp.2016.41

52. Ziegler C, Wolf C, Schiele M, Ferić Bojić E, Kučukalić S, Šabić Džananović E et al.: Monoamine oxidase A gene methylation and its role in Posttraumatic Stress Disorder - First evidence from the South Eastern Europe (SEE)PTSD study. Int J Neuropsychopharmacol 2018; 00:1-10. doi: 10.1093/ijnp/pyx111/4653

Correspondence:

Nermina Kravić, MD, PhD

Department of Psychiatry, University Clinical Centre Tuzla

Rate Dugonjića bb, 75000 Tuzla, Bosnia and Herzegovina

E-mail:nahlica@yahoo.com 